\title{
Design of Computer Integrated Safety and Health Management System
}

\author{
Hunszu Liu \\ Industrial Engineering and Management, Ming Hsin University of Science and Technology, \\ No. 1 Hsin-Hsing Road, Hsin-Fong, Hsinchu, Taiwan \\ hliu@must.edu.tw
}

\begin{abstract}
Diverse safety and health operation data collected and stored in different departments have not been fully integrated and utilized by managers due to poor design of safety and health information system. The safety and health management system can be depicted, conceptually, as an organic system with circulation of information flow which carries required data and information to specified workers and initiates appropriate responses respectively. This study is targeting to solve the problems of current safety and health management system through the integration of human information processing theory, certified safety and health management assessment guidelines and regulations, and IT techniques. The objective of this study is to propose a framework of computer integrated safety and health management system.
\end{abstract}

Keywords: Safety and health management, safety information, computer integrated management system.

\section{Introduction}

Various safety and health management system were developed to meet the requirements of government law and regulations. Among them, two types are most commonly used, the traditional method of safety, and the methods and philosophies of quality in conjunction with safety. The traditional methods of safety established standard procedures to direct and control workers. Management programs are in place to modify the behavior of workers, to motivate their participation, and to reward their compliance. This approach centers exclusively on the technical requirements and on obtaining short-term results. Another shortcoming of this approach is its isolation with the rest of functions of organizations [1], [2]. In recent year, the concept of integrate safety and quality is widely accept by safety practitioners to reinforce the weakness of traditional approach. Total safety management (TSM), written and practiced using the principles of total quality management (TQM), was introduced to industry [3], [4], [5], [6]. However, these management programs do not always improve the results of safety. This is because diverse safety and health operation data collected and stored in different departments have not been fully integrated and utilized by managers due to poor design of safety and health information system. 
Decisions are made based on insufficient information, thus decreasing the robustness of system safety barriers.

The safety and health management system should not only meet the regulation requirements, which are the minimum requirement, but also act as an effective information processing system which means it can handle and store stimuli generated from system components and capable of performing perception, decision and response selection, and response execution functions. In other words, the system should function as an organic system with circulation of information flow which carries required data and information to specified workers and initiates appropriate responses respectively. This study is targeting to solve the problems of current safety and health management system through the integration of human information processing theory, certified safety and health management assessment guidelines and regulations, and IT techniques. The objective of this study is to propose a framework of computer integrated safety and health management system.

\section{Background Information}

The advent of technology has significantly increased the scope and paces of safety and health management activities. Information, intelligence, and computer techniques were widely applied in industry environment. These techniques reduce the burden of manual operations such as data collection, environment detection, and data transformation. More activities can be included in the safety and health management program. But the amounts of data generated from these devices are also increased. As a result, the workloads of safety and health personnel have been changed from physical activities to psychological activities. Most manual works have been replaced by mental works. The success of this change relies heavily on the design of safety and health management system (SHMS).

A well designed safety and health management system should meet the organization needs. The magnitude of organization and manufacturing characteristics are two important factors to decide the scope and complexity of SHMS. While multination corporations can spend enough resources to establish and maintain complex SHMS, small enterprise barely has designated personnel in charge of safety and health issues. To balance the differences between organizations and set an objective criteria for assessing the SHMS, safety and health standards or guidelines, national or international, are developed. Among them, Process Safety Management (PSM), Voluntary Protection Program (VPP), Responsible Care (RC), International Safety Rating System (ISRS) [7], [8], [9], and Occupational Health and Safety Assessment Series 18000 (OHSAS 18000) [10], [11] are the most popular in local industry. These standards or guidelines focus on the establishment of safety and health management system mechanisms. Fulfilled the requirements and passed the assessment process indicate organizations are embedded with a certified safety and health management system. It is argued that these mechanisms, accompanied by scheduled audit process, will continually improve organization safety status.

One problem of these approaches is that these methods are developed and tested through pragmatic practical approaches, which have not been scientifically validated.

Another problem is that these requirements are either too general to be used directly by plant managers to construct its safety and health management system or 
too strict to be used by small companies. The safety and health management system must fulfill the requirements of general accepted standards as well as industrial managers' expectations. Therefore, the safety and health practitioners' opinions must be incorporated into the developing process. The third problem is that these systems usually act as an isolate system. In order to fulfill the requirements of these systems in very short time, organizations usually form a temporary project team in charge of the implementation process. The project teams members come from different departments develop appropriate measurements through extra-working hours. Their performances are rated based on the final audit results. It is likely to ignore activities which are not required by those systems. Many safety and health activities current carried out within the organization will not be included in the system. As a result, these systems usually operated without integration with existing safety and health system.

\section{Methodology}

The process of developing computer integrated safety and health management system is divided into three stages. The objective of stage I is to develop the components of system. Stage II focuses on the program development. Stage III is the implementation and risk assessment stage. This paper describes works performed in stage I. In order to explore the components of a well designed safety and health management three most widely implemented safety and health management system in local industry, including Process Safety Management (PSM), Voluntary Protection Program (VPP), and Occupational Health and Safety Assessment Series 18000 (OHSAS 18000), are studied. The functional requirements of these components and corresponding activities are identified through interviewing with industry personnel. Questionnaires were developed through literature review. The components are classified into three categories, including Occupational Health and Safety Condition (OHSC), Occupational Health and Safety Management (OHSM), and Occupational Health and Safety Operation (OHSO). A Total of thirty-two items was identified (Table 1).

The Analytic Hierarchy Process (AHP), developed by Thomas L. Saaty, is used as the tool to analyze the collected questionnaires. Each participant was required to provide judgments about the relative importance of each component.

The questionnaire is divided into two parts. Part I. pair wise compares the priorities of the three categories: OHSC, OHSM, and OHSO. Part II. pair wise compares the priorities of the components within each category respectively. The comparison scale for the importance of criteria is classified into nine levels and converted into numerical level from 1-9: (from equally important to extremely more important).

\section{Results and Discussions}

Thirty senior safety and health experts with at least ten years of related experiences were asked to answer the questionnaires. Eighteen questionnaires were collected and analyzed to identify the necessity and importance of these criteria. The analyzed results indicate that the priorities for three safety and health management system categories are: A. (OHSC, 1.36), B. (OHSM, 1.68), and C. (OHSO, 0.96). The OHSC 
reflects the general condition of the whole safety and health management system and the OHSO indicates the operational level status. The results indicate that for plant managers the image of safety and health management system and operational status are their major concerns.

The rankings of safety and health management system components are listed in table 2. The implementation of safety and health program and employee safety behavior are the most important component for a well designed $\mathrm{S} \& \mathrm{H}$ management

Table 1. Safety and Health Management System Component

\begin{tabular}{ll}
\hline \multicolumn{1}{c}{ Categories } & \multicolumn{1}{c}{ Components } \\
\hline A.OHSC & A1:Occupational injury and disease condition \\
A2:Operational environment quality \\
A3:Working Plant Health and Safety Condition \\
A4:Legal Compliance \\
A5:Employee Health Inspection Condition \\
A6:Employee Safety Awareness \\
A7:Employee Safety Behavior \\
A8:Mechanical Equipment Safety Status \\
A9:Safety Climate \\
B1:Management Review \\
B2:Safety Audit \\
B3:Achieving Objectives \\
B4:Health and Safety Improvement Program \\
B5:Employee Suggestion Program \\
B6:Health and Safety Promotion Activities \\
B7:Corrective and Preventive Action \\
B8:Customer or Community Complaints \\
C1:Top Management Inspection \\
C2:Implementation of the Training Program \\
C3:Implementation of Health and Safety program \\
C4:Implementation of the Self Inspection Program \\
C5:Implementation of the Emergency Response Program \\
C6:Implementation of the Occupational Injury and Disease \\
Prevention Program \\
C7:Dangerous Machinery and Equipment Operation Condition \\
C8:Occupational Injury and Disease Report and Treatment \\
Condition \\
C9:Operational Control Condition \\
C10:Contractor control Condition \\
C11:Consultation and Communication Condition \\
C12:Personal Protective Equipment Operating Condition \\
C13:Toxic and Danger Substances Management Condition \\
C14:Implementation of the Process Safety Assessment and Risk \\
Assessment \\
C15:Measurement Equipment Calibration Condition \\
C.OHSO
\end{tabular}


Table 2. Ranking of safety and health management system performance indicators

\begin{tabular}{llllll}
\hline rank & $\begin{array}{l}\text { performance } \\
\text { indicators }\end{array}$ & priority & rank & $\begin{array}{l}\text { performance } \\
\text { indicators }\end{array}$ & priority \\
\hline 1 & C3 & 1.82 & 17 & A3 & 0.94 \\
2 & A7 & 1.78 & 18 & A5 & 0.92 \\
3 & C5 & 1.48 & 19 & A1 & 0.9 \\
4 & B3 & 1.41 & 20 & B7 & 0.8 \\
5 & C1 & 1.36 & 21 & C12 & 0.8 \\
6 & A6 & 1.33 & 22 & C13 & 0.8 \\
7 & A4 & 1.21 & 23 & C9 & 0.79 \\
8 & B2 & 1.2 & 24 & A2 & 0.76 \\
9 & C14 & 1.15 & 25 & B1 & 0.74 \\
10 & C6 & 1.13 & 26 & C11 & 0.66 \\
11 & C7 & 1.11 & 27 & A8 & 0.62 \\
12 & C2 & 1.08 & 28 & A9 & 0.54 \\
13 & C4 & 1.01 & 29 & C8 & 0.48 \\
14 & B5 & 1 & 30 & B8 & 0.45 \\
15 & C10 & 1 & 31 & B6 & 0.41 \\
16 & B4 & 0.99 & 32 & C15 & 0.33 \\
\hline
\end{tabular}

system. The measurement equipment calibration condition and health and safety promotion activities are the least important component. These results concur with previous conclusion that the image of safety and health management system and operational status are their major concerns.

\section{Discussions}

As the manufacturing system progressing toward the lean manufacturing system era, the tolerance for deviation from normal operations becomes more tightly than ever before. The unexpected breakdown of safety and health management system can initiate chain reactions of business interruptions, once the system safety barriers are unable to protect the disturbances from either technical or human failure, which might endanger business survivals for companies involved. In order to ensure the smooth operation of manufacturing activities, safe working environment must be achieved through robust design on defense in depth and effective safety management system. However, the working environment will not stay the same. The changing manufacturing scenario created by aging facilities and inconstant human performance has put the effectiveness and efficiency of deployed program in doubt. As a result, to ensure the proper implementation of safety and health management system and maintain the on-going process of fulfilling the organizational needs, it is necessary for companies to have a well designed safety and health management system which can serve managers' needs.

Traditionally, company managers receive safety and health related information through the feedback of the company's safety and health accident records. As a result, companies can only realize the safety and health problems when something went wrong. To reduce the consequence of the trial-and-error approach adopted currently by many organizations, it is necessary to develop a computer integrated safety and 
health management system, which can help company managers assessing the management system status.

The purpose of this study is to develop a framework of computer integrated safety and health management system. Related researches are reviewed and expert knowledge is incorporated. The study results can provide the system developer the capability to construct the safety and health management system.

\section{Future Works}

This study discusses partial research results of three years project. The components of a well designed safety and health management system are investigated. The next step is to analyze these activities and construct the information system through Business System Planning (BSP) technique. Components are grouped together based on the expected functions performed under the human information processing model. The data collected at each department or working site through sensors or manual entry play as stimuli, which represent current system status of the information processing system. Components are designed to perceive and process these stimuli. Functions of tools to help decision maker select proper responses are identified. IDEF $\varnothing$ technique is adopted to model the decisions, actions, and activities of safety and health management system. In order to maintain the effectiveness of safety and health management the Plan-Do-Check-Action (PDCA) principle are embedded in the system. This means labor intensive works are needed to process system operation information. Computer integrated safety and health management system can not only alleviate the burden of paper works but also provide efficient way of accessing these data.

Acknowledgments. The authors would like to thank the National Science Council for supporting this project (project \# NSC\#95-2221-E-159-005)

\section{References}

1. Smith, T.A: Will safety be ready for workplace 2000. Professional Safety 41(2), 37-38 (1996)

2. Herrero, S.G., Saldan, M., et al.: From the traditional concept of safety management to safety integrated with quality. Journal of Safety Research 33, 1-20 (2002)

3. Rahimi, M.: merging strategic safety, health and environment into total quality management. International Journal of Industrial Ergonomics 16, 83-94 (1995)

4. Weinstein, M.H.: Improving safety program through total quality, Occupational Hazards, 58(8) (1996)

5. Goetsch, D.: Implementing Total Safety Management. Prentice Hall, New Jersey (1998)

6. Sznaider, B.A.: TQM can make plants safer. Manufacturing Engineering 121(5), 144 (1998)

7. Bird, F.E., Germain, G.L.: Practical Loss Control Leadership, International Loss Control Institute, Georgia, USA (1990)

8. Eisner, H.S., Leger, J.P.: The International Safety Rating System in South African Mining. Journal of Occupational Accidents 10, 141-160 (1988) 
9. Gaunt, L.D.: The effect of the International Safety Rating System on organizational performance. Centre for Risk Management \& Insurance Research. Georgia State University, Research Reports Service. 89-2. Atlanta, Georgia (1989)

10. British Standards Institution,BS 8800, Guide to Occupational Health and Safety Management System (1996)

11. BS 8800: Guide to Occupational health and safety management systems,BSI, UK (1996) 